\title{
Rheology of Sesame Pastes with Different Amounts of Water Added
}

\author{
Li-Xia Hou \\ College of Food Science and Technology, Henan University of Technology, Lian-Hua Street, \\ Zhengzhou 450001, China
}

Correspondence should be addressed to Li-Xia Hou; hou1269@126.com

Received 9 August 2017; Revised 13 September 2017; Accepted 26 September 2017; Published 25 October 2017

Academic Editor: Ji Kang

Copyright (C) $2017 \mathrm{Li}$-Xia Hou. This is an open access article distributed under the Creative Commons Attribution License, which permits unrestricted use, distribution, and reproduction in any medium, provided the original work is properly cited.

\begin{abstract}
Sesame paste, usually served as a dressing in some local dishes and the desserts in Southeast Asia and the Middle East, requires mixing with water before consumption to form a thin emulsion of the oil-in-water type. Usually water addition is performed empirically and it is difficult to keep the quality of water-mixed sesame paste consistent. In this study, the rheological behavior of sesame paste with different ratios of sesame paste to added water was investigated. The sesame paste tested contains $59.71 \%$ of crude fat and $17 \%$ of protein. The ratios of sesame paste to added water (w/v) were 1:0.75 (T1), 1:1 (T2), 1:1.25 (T3), and 1:1.5 (T4), respectively. All the samples showed the properties of the viscoelastic solids. The samples T1 and T2 behaved as a pseudoplastic material, whereas the apparent viscosity of T3 and T4 remained almost unchanged with the shear rate increasing. T2 had the moderate area of thixotropy loop $(57.32 \mathrm{~Pa} / \mathrm{s})$ among the tested samples and scored the highest in the sensory evaluation. Therefore, our study suggested that ratio of sesame paste to added water of $1: 1(\mathrm{w} / \mathrm{v})$ is suitable for preparing dressings for different dishes.
\end{abstract}

\section{Introduction}

Sesame paste, a suspension of the hydrophilic particles dispersed in the oil, has an oil content of approximately $60 \%$ and is a typical oil condiment [1].

Commercial sesame paste is often viscous and required mixing with water before consumption [2]. Usually water addition is performed empirically and mainly judged by sensory taste, which is not suitable for preparing large amount of sesame paste; therefore, it is hard to meet the need in the hotpot or dry noodle industry when homogeneous mixing and consistent taste are required for large amount of sesame paste. The previous studies of rheological properties of sesame paste allow us to understand not only the changes in the texture and structure of sesame paste, but also the variation pattern of mechanical properties related to processing $[1,3-$ 7]. However, the contribution of water addition to the overall rheological properties of the sesame paste has not been studied. The objectives of this study were to investigate the rheological behaviour of sesame paste as a function of water addition and determine the suitable amount of water added to the sesame paste when being used as the dressing and other condiments.

\section{Materials and Methods}

2.1. Samples. The commercial sesame paste sample was obtained from "Ruifu Oil and Fat Co. Ltd" (Weifang, China), which was made from the white sesame seed; its proximate composition was shown in Table 1. A certain amount of water was slowly added to sesame paste of $10 \mathrm{~g}$ in the beaker, and then, the mixture was stirred with the glass-stick for about $5 \mathrm{~min}$ to get the homogeneous emulsion. The ratios of sesame paste to water $(\mathrm{w} / \mathrm{v})$ were $1: 0.75,1: 1,1: 1.25$, and $1: 1.5$, and labeled as T1, T2, T3, and T4, respectively; all the samples were prepared just before the rheological test and allowed to rest for $10 \mathrm{~min}$ prior to measurement. The sesame paste without adding water was used as the control, labeled as CK. All reagents used were of analytical grade.

2.2. Analytical Methods. The content of protein, moisture, ash, and fat in the sesame paste was determined using the 
TABLE 1: Chemical components and acid values of the sesame paste sample* ${ }^{*}$

\begin{tabular}{lccccccc}
\hline Sesame paste & $\begin{array}{c}\text { Crude fat } \\
(\%)\end{array}$ & $\begin{array}{c}\text { Protein } \\
(\%)\end{array}$ & $\begin{array}{c}\text { Crude fibre } \\
(\%)\end{array}$ & $\begin{array}{c}\text { Total sugars } \\
(\%)\end{array}$ & $\begin{array}{c}\text { Total ash } \\
(\%)\end{array}$ & $\begin{array}{c}\text { Moisture content } \\
(\%)\end{array}$ & $\begin{array}{c}\text { Acid values } \\
(\mathrm{mgKOH} / \mathrm{g})\end{array}$ \\
\hline CK & $59.71 \pm 0.26$ & $17.00 \pm 0.13$ & $3.78 \pm 0.10$ & $7.70 \pm 0.16$ & $5.01 \pm 0.01$ & $0.12 \pm 0.02$ & $1.07 \pm 0.10$ \\
\hline
\end{tabular}

${ }^{*}$ The components are expressed on dry weight basis except moisture content.

methods of the Association of Official Analytical Chemists (AOAC, 2000) [8]. The content of fibre was determined according to van Soest et al. [9].

2.3. Measurement of the Rheological Properties. The rheological properties of the sesame paste were measured using A HAAKE Rheostress 60 rheometer. A power law model was used to fit the data as follows:

$$
\tau=k * \gamma^{n}
$$

where $\tau$ is the shear stress, $\mathrm{Pa} ; \gamma$ is the shear rate, $1 / \mathrm{s} ; k$ is the consistency coefficient, $\mathrm{Pa} \cdot \mathrm{s}$; and $n$ is the flow index.

2.4. Sensory Evaluation. The sensory evaluation was determined by ten semitrained panelists. Six attributes including color and lustre, smell, texture, and taste were used to describe the sensory characteristics of the sesame paste. Every attribute was scored from 0 (attribute bad or abnormal) to 5 (attribute good and characteristic), and the data presented were the average of ten scores.

2.5. Data Analysis. All the data were analysed with the HAAKE Rheowin Data Manager 4.63.000, SPSS 16.0, and Excel 2003.

\section{Results and Discussion}

3.1. Proximate Composition. Table 1 showed that the sesame paste tested in this study contains $59.71 \%$ of crude fat, $17.00 \%$ of protein, $3.78 \%$ of crude fibre, $7.70 \%$ of total sugars, and $5.01 \%$ of total ash, respectively. The acid value was $1.07 \mathrm{mgKOH} / \mathrm{g}$. The content of crude fat was similar to the roasted sesame seeds of two kinds of sesame in Cameroon [10] but higher than that of the raw sesame seeds produced in Syria [11] and Sudan [12]. This may be due to the fact that the preparation of the sesame paste involves the roasting procedure, which resulted in somewhat dehulling and the loss of water, and thus the content of crude fat was relatively elevated.

3.2. Static Rheological Properties. The shear stress versus shear rate behaviour of the sesame paste with different amount of added water was measured at $25^{\circ} \mathrm{C}$ (Figure 1). The results showed that, at the same shear rate, $\mathrm{T} 1$ exhibited the greatest shear stress, whereas T4 exhibited the lowest shear stress. Interestingly, the initial shear stress of T2 was greater than that of CK; however, it was lower than that of $\mathrm{CK}$

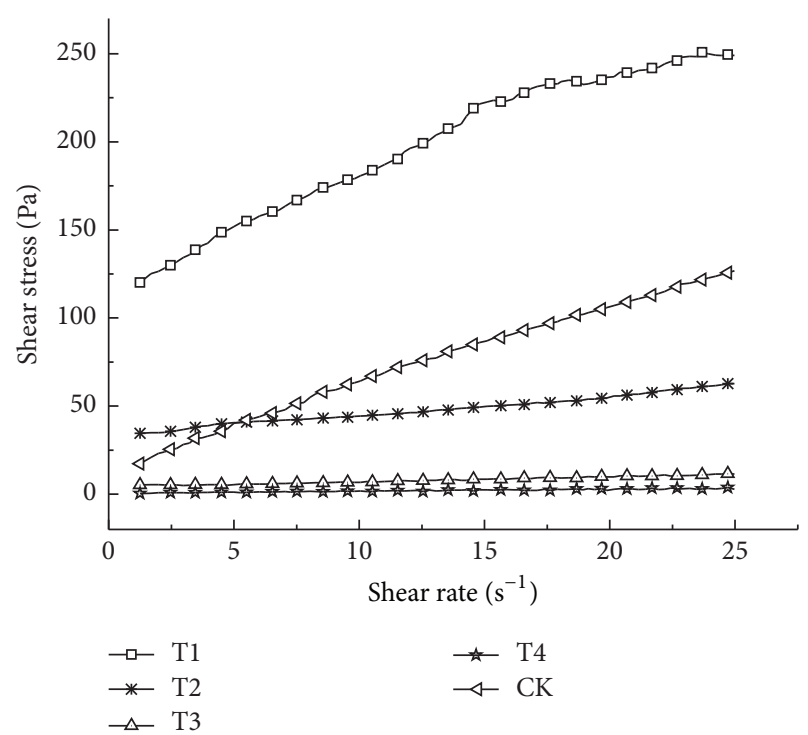

FIGURE 1: Flow curves of the sesame paste with different amounts of water (T1, T2, T3, and T4: the ratios of sesame paste to water $(\mathrm{w} / \mathrm{v})$ were $1: 0.75,1: 1,1: 1.25$, and $1: 1.5$, resp.; CK: the sesame paste without adding water).

when the shear rate was higher than $5 \mathrm{~S}^{-1}$. The shear stress of T3 and T4 maintained the same level despite increasing the shear rates. We suspected that the molecular interactions of T3 and T4 were weak which made the samples flow easily.

The effect of the shear rate of the sesame paste on the apparent viscosity was also tested in this study (Figure 2). The results showed that samples $\mathrm{T} 1, \mathrm{~T} 2$, and control CK performed a shear thinning behaviour like a pseudoplastic material in which the apparent viscosity decreased when the shear rates increased. This result was consistent with that of hulled and unhulled sesame paste [6], milled sesame [13], and sweetened sesame paste [7].

The apparent viscosity of T1 (ratio of paste/water was 1:0.75) was the highest at first but decreased fast with the shear rate increasing. The apparent viscosities of the rest of the sesame paste samples decreased slowly with increasing shear rates (Figure 2). The initial apparent viscosities of T3 (ratio of paste/water was $1: 1.25$ ) and $\mathrm{T} 4$ (ratio of paste/water was $1: 1.5)$ were low and remained stable with increasing shearing rates, indicating that these two sesame paste samples were too dilute and thin; therefore, these two ratios of paste and water are not suitable for salad dressing. The initial apparent 


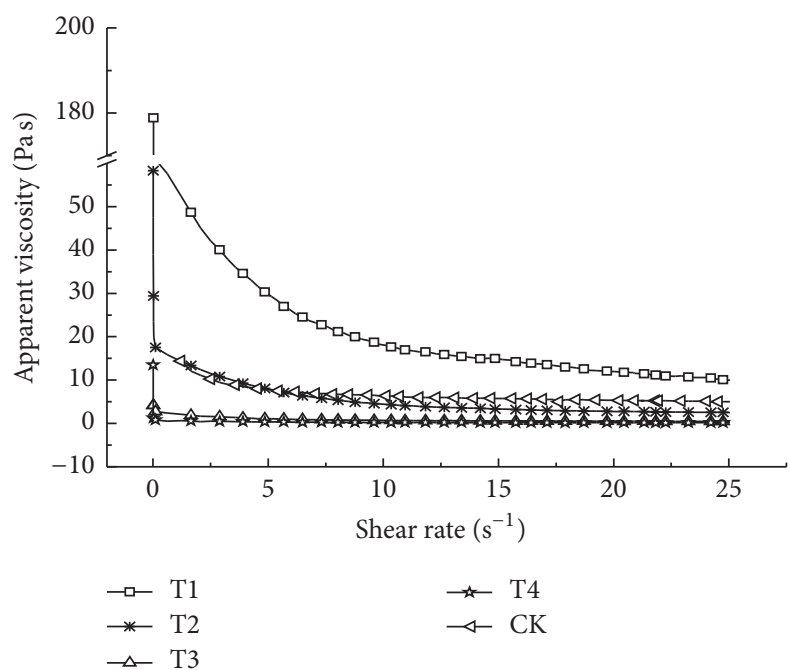

FIGURE 2: Relationship between the shear rate and apparent viscosity of the sesame paste with various amounts of water.

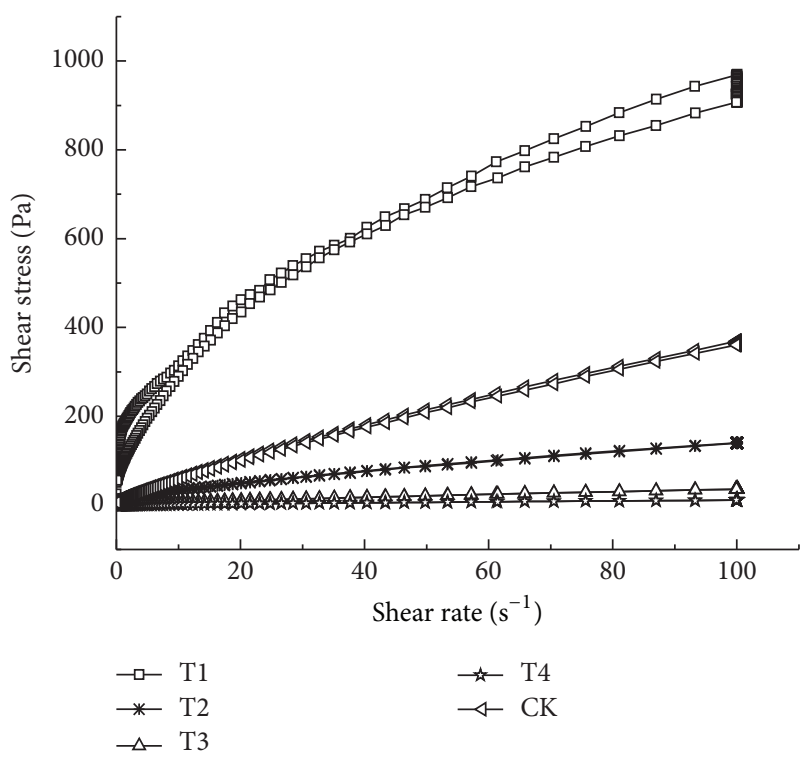

FIGURE 3: Thixotropy measurements of the sesame paste with different amounts of water.

viscosity of T2 (ratio of paste/water was 1:1) was similar to that of the original sesame paste; however, its apparent viscosity decreased rapidly when the shear rate increased, indicating that the ratio of paste and water at $1: 1$ has the excellent tackiness at stationary conditions and flows easily while stirring; thus, ratio of $1: 1$ is suitable for salad dressing and hot pot dishes.

3.3. Thixotropy. The thixotropy loop was obtained by increasing, holding, and decreasing the shear rate of samples (Figure 3). The areas of the thixotropy loops represent the
TABLE 2: Areas of thixotropy loops of sesame paste with different amounts of water.

\begin{tabular}{lccccc}
\hline Sample & T1 & T2 & T3 & T4 & CK \\
\hline $\begin{array}{l}\text { Area of } \\
\text { thixotropy }\end{array}$ & 3500.00 & 57.32 & 21.00 & 8.14 & 500.00 \\
loop (Pa/s) & & & & & \\
\hline
\end{tabular}

energy of the samples to eliminate the time-dependent effect on rheological behaviour [14] (Table 2).

The results showed that when the paste and water ratio was at 1: 0.75 (sample T1), the shear stress increased fast with the shear rate increased, which reached as high as $970 \mathrm{~Pa}$ (Figure 3). Meanwhile, the area of the thixotropic loop was also the highest when the ratio of sesame paste and water was at 1:0.75, which was 61 times larger than that of $1: 1$ ratio (sample T2) (Table 2) and about 3 times larger than yogurts [15], which indicated that it may require longer time to recover to original structure when the sesame paste and water ratio was at $1: 0.75$. The sesame paste and water ratio of $1: 1.5$ (sample T4) showed the smallest area of the thixotropic loop, $8.14 \mathrm{~Pa} / \mathrm{s}$, which indicated that it is extremely easy to recover to original structure when adding 1.5 times the amount of water to the sesame paste. T2 showed a moderate thixotropy loop area of $57.32 \mathrm{~Pa} / \mathrm{s}$.

3.4. Dynamic Viscoelasticity. Dynamic oscillatory shear test was used to characterize the relationship between viscoelastic properties of the sesame paste samples and the changes of $G^{\prime}$ (the storage modulus) and $G^{\prime \prime}$ (the loss modulus) (Figure 4). $G^{\prime}$ represents the energy stored in the material; $G^{\prime \prime}$ indicates the measurement of energy dissipated during every cycle [16]. If $G^{\prime} \geq G^{\prime \prime}$, the samples present characteristics of viscoelastic solids; if $G^{\prime} \leq G^{\prime \prime}$, the samples show characteristics of fluids [17]. The results showed that $1: 0.75$ (T1) and $1: 1.5$ ratio (T4) of sesame paste and water displayed the highest and the lowest storage modulus $G^{\prime}$, respectively. However, all the samples showed higher $G^{\prime}$ than the loss modulus $G^{\prime \prime}$ when the frequency range was within $0.1-10 \mathrm{~Hz}$ (Figure 4), which demonstrated a behaviour of a gel and the properties of a viscoelastic solid [18].

3.5. Sensory Evaluation. The sensory evaluation of sesame paste with different ratio of water was assessed and the results were analysed (Table 3 ). The ratio of 1: 0.75 (T1) and $1: 1.5$ (T4) showed the lowest texture and total sensory score. The ratio of $1: 1$ (T2) showed the highest total score which exhibited a light yellow color and lustre, a rich and typically aromatic smell of sesame paste, and appropriate viscosity. Therefore, the results of our study showed that the ratio of sesame paste and water at 1:1 is suitable for salad dressing and hot pot dishes.

\section{Conflicts of Interest}

The author declares that there are no conflicts of interest regarding the publication of this paper. 


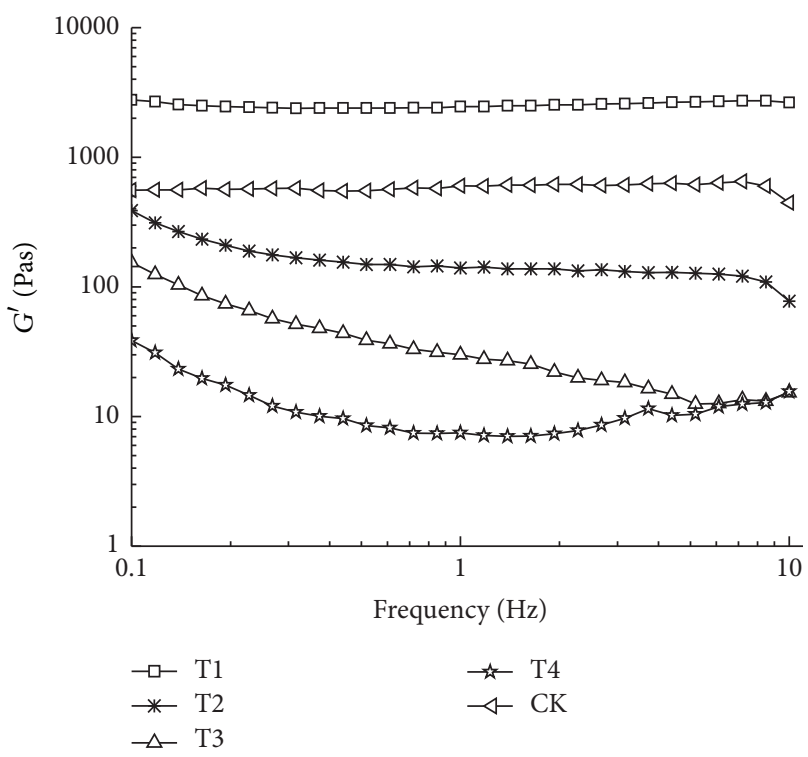

(a)

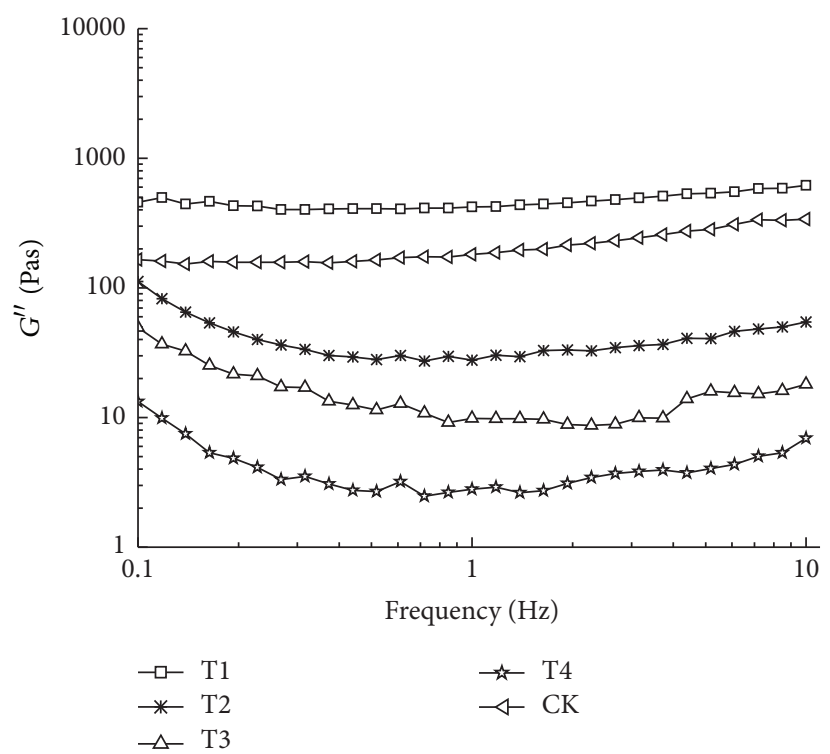

(b)

FIGURE 4: Frequency sweep charts of the sesame paste with different amounts of water: (a) storage modulus and (b) loss modulus.

TABLE 3: Sensory evaluation of different ratio of sesame paste and water.

\begin{tabular}{lccccc}
\hline Sample & Colour and lustre & Smell & Texture & Taste & Total score \\
\hline T1 & 3 & 2 & 1 & 5 & 8 \\
T2 & 4 & 5 & 5 & 3 & 19 \\
T3 & 4 & 3 & 3 & 2 & 13 \\
T4 & 2 & 2 & 1 & 4 & 7 \\
CK & 5 & 5 & 4 & & 18 \\
\hline
\end{tabular}

\section{Acknowledgments}

This work was supported by the Henan Provincial Scientific and Technological Research Project (Grant no. 152102210272, 2015).

\section{References}

[1] F. L. Altayand and M. M. Ak, "Effects of temperature, shear rate and constituents on rheological properties of tahin (sesame paste)," Journal of the Science of Food \& Agriculture, vol. 85, no. 1, pp. 105-111, 2005.

[2] P. Lindner and J. E. Kinsella, "Study of the hydration process in tehina," Food Chemistry, vol. 42, no. 3, pp. 301-319, 1991.

[3] D. Çiftçi, T. Kahyaoglu, S. Kapucu, and S. Kaya, "Colloidal stability and rheological properties of sesame paste," Journal of Food Engineering, vol. 87, no. 3, pp. 428-435, 2008.

[4] M. Al-Mahasneh, T. Rababah, and M. Alu'Datt, "Effect of palm oil (PO) and distilled mono-glycerid (Dmg) on oil separation and rheological properties of sesame paste," Journal of Food Processing \& Preservation, pp. 1-8, 2016.

[5] M. Akbulut, C. Saricoban, and M. M. Ozcan, "Determination of Rheological Behavior, Emulsion Stability, Color, and Sensory of Sesame Pastes (Tahin) Blended with Pine Honey," Food and Bioprocess Technology, vol. 5, no. 5, pp. 1832-1839, 2012.
[6] M. Akbulut and H. Çoklar, "Physicochemical and rheological properties of sesame pastes (tahin) processed from hulled and unhulled roasted sesame seeds and their blends at various levels," Journal of Food Process Engineering, vol. 31, no. 4, pp. 488-502, 2008.

[7] B. Abu-Jdayil, "Flow properties of sweetened sesame paste (halawa tehineh)," European Food Research and Technology, vol. 219, no. 3, pp. 265-272, 2004.

[8] AOAC, Official Methods of Analysis of the Association of Official Analytical Chemists, Association of Official Analycal Chemists, Washington, D.C., USA, 19th edition, 2000.

[9] P. J. van Soest, J. B. Robertson, and B. A. Lewis, "Methods for dietary fibre, neutral detergent fiber, and non starch carbohydrates in relation to animal nutrition," Journal of Dairy Science, vol. 74, no. 10, pp. 3583-3597, 1991.

[10] N. Tenyang, R. Ponka, B. Tiencheu et al., "Effects of boiling and roasting on proximate composition, lipid oxidation, fatty acid profile and mineral content of two sesame varieties commercialized and consumed in Far-North Region of Cameroon," Food Chemistry, vol. 221, pp. 1308-1316, 2017.

[11] M. Al-Bachir, "Some microbial, chemical and sensorial properties of gamma irradiated sesame (Sesamum indicum L.) seeds," Food Chemistry, vol. 197, pp. 191-197, 2016.

[12] M. Elleuch, S. Besbes, O. Roiseux, C. Blecker, and H. Attia, "Quality characteristics of sesame seeds and by-products," Food Chemistry, vol. 103, no. 2, pp. 641-650, 2007. 
[13] B. Abu-Jdayil, K. Al-Malah, and H. Asoud, "Rheological characterization of milled sesame (tehineh)," Food Hydrocolloids, vol. 16, no. 1, pp. 55-61, 2002.

[14] S. Razmkhah, S. M. A. Razavi, and M. A. Mohammadifar, "Dilute solution, flow behavior, thixotropy and viscoelastic characterization of cress seed (Lepidium sativum) gum fractions," Food Hydrocolloids, vol. 63, pp. 404-413, 2017.

[15] E. C. Ale, M. J. Perezlindo, Y. Pavón et al., “Technological, rheological and sensory characterizations of a yogurt containing an exopolysaccharide extract from Lactobacillus fermentum Lf2, a new food additive," Food Research International, vol. 90, pp. 259-267, 2016.

[16] N. Singh Sodhi and N. Singh, "Morphological, thermal and rheological properties of starches separated from rice cultivars grown in India," Food Chemistry, vol. 80, no. 1, pp. 99-108, 2003.

[17] L. Ma and G. V. Barbosa-Cánovas, "Rheological characterization of mayonnaise. Part II: Flow and viscoelastic properties at different oil and xanthan gum concentrations," Journal of Food Engineering, vol. 25, no. 3, pp. 409-425, 1995.

[18] N. G. Diftis, C. G. Biliaderis, and V. D. Kiosseoglou, "Rheological properties and stability of model salad dressing emulsions prepared with a dry-heated soybean protein isolate-dextran mixture," Food Hydrocolloids, vol. 19, no. 6, pp. 1025-1031, 2005. 

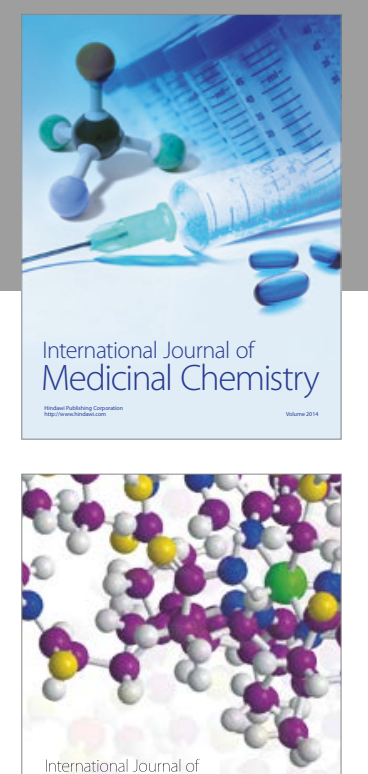

Carbohydrate Chemistry

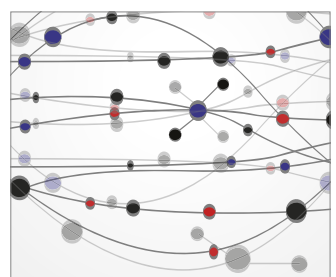

The Scientific World Journal
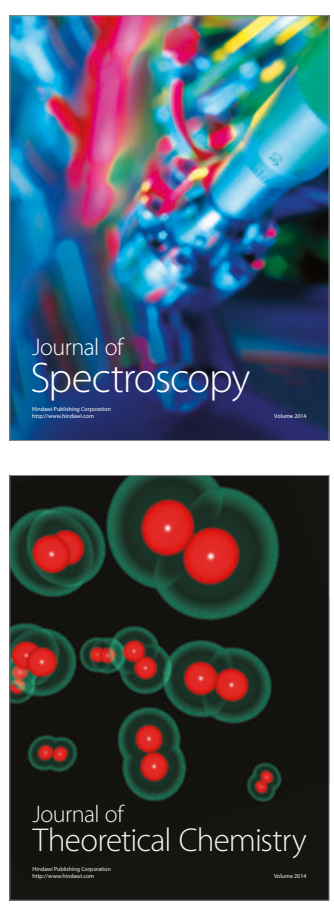
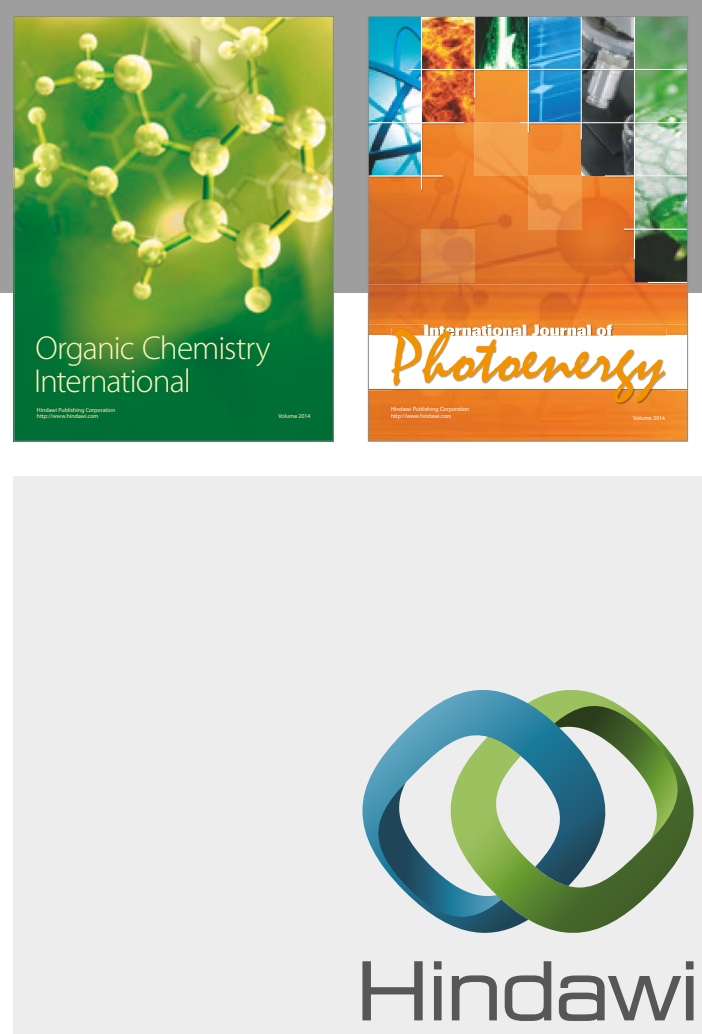

Submit your manuscripts at

https://www.hindawi.com

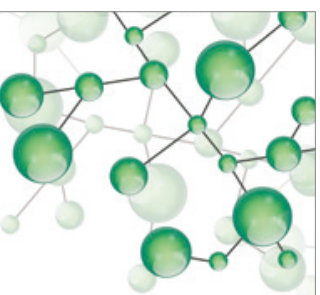

International Journal of

Inorganic Chemistry

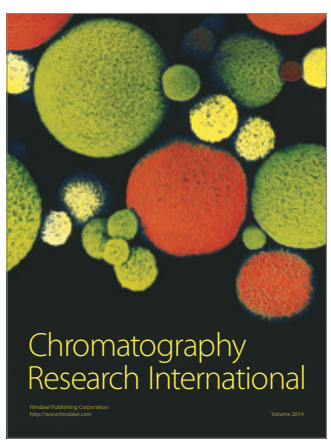

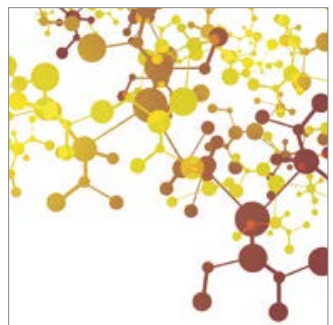

Applied Chemistry
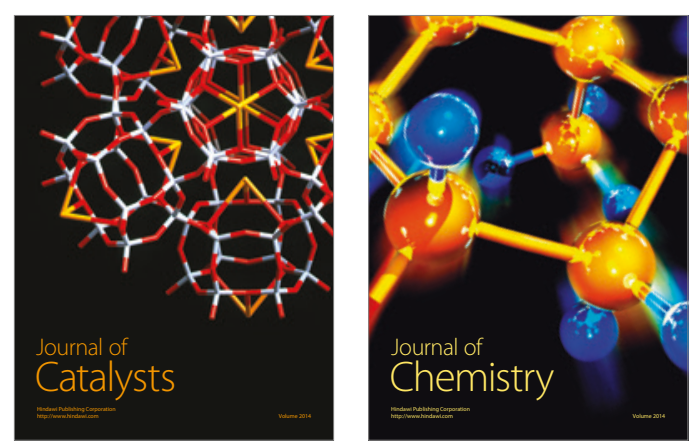
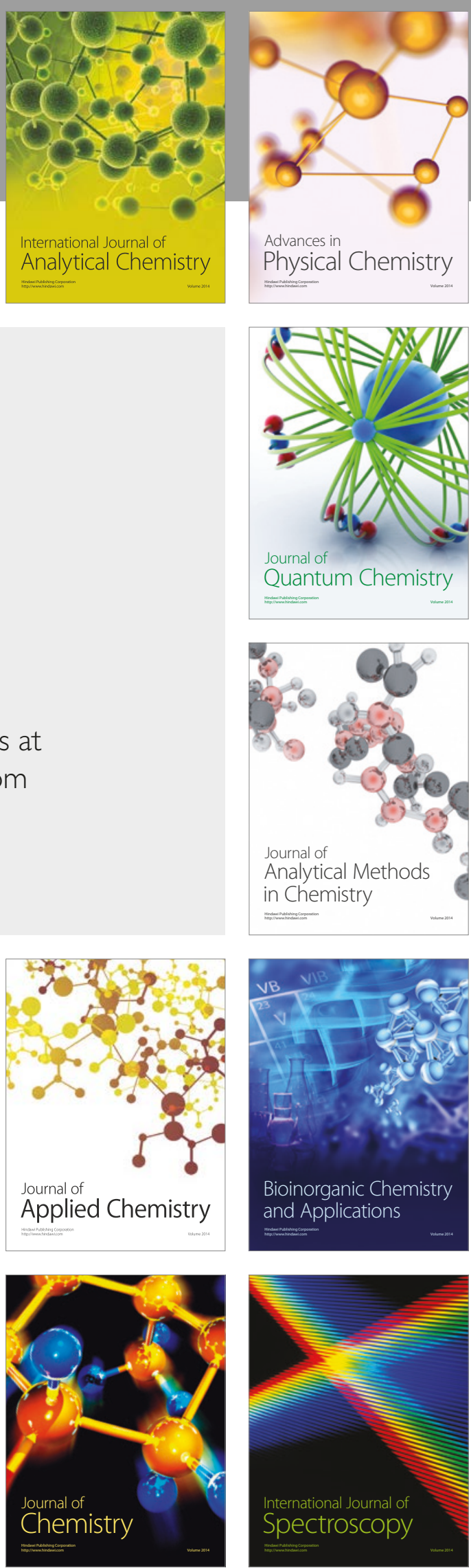